\title{
Comparison of GEOS-5 AGCM planetary boundary layer depths computed with various definitions
}

\author{
E. L. McGrath-Spangler ${ }^{1,2}$ and A. Molod $^{2,3}$ \\ ${ }^{1}$ Universities Space Research Association, Columbia, MD, USA \\ ${ }^{2}$ Global Modeling and Assimilation Office, NASA GSFC, Greenbelt, MD, USA \\ ${ }^{3}$ Earth System Sciences Interdisciplinary Center, University of Maryland, College Park, MD, USA \\ Correspondence to: E. L. McGrath-Spangler (erica.1.mcgrath-spangler@nasa.gov)
}

Received: 15 January 2014 - Published in Atmos. Chem. Phys. Discuss.: 12 March 2014

Revised: 20 May 2014 - Accepted: 27 May 2014 - Published: 3 July 2014

\begin{abstract}
Accurate models of planetary boundary layer (PBL) processes are important for forecasting weather and climate. The present study compares seven methods of calculating PBL depth in the GEOS-5 atmospheric general circulation model (AGCM) over land. These methods depend on the eddy diffusion coefficients, bulk and local Richardson numbers, and the turbulent kinetic energy. The computed PBL depths are aggregated to the Köppen-Geiger climate classes, and some limited comparisons are made using radiosonde profiles. Most methods produce similar midday PBL depths, although in the warm, moist climate classes the bulk Richardson number method gives midday results that are lower than those given by the eddy diffusion coefficient methods. Additional analysis revealed that methods sensitive to turbulence driven by radiative cooling produce greater PBL depths, this effect being most significant during the evening transition. Nocturnal PBLs based on Richardson number methods are generally shallower than eddy diffusion coefficient based estimates. The bulk Richardson number estimate is recommended as the PBL height to inform the choice of the turbulent length scale, based on the similarity to other methods during the day, and the improved nighttime behavior.
\end{abstract}

\section{Introduction}

The planetary boundary layer (PBL) depth is important for surface-atmosphere exchanges of heat, moisture, momentum, carbon, and pollutants. Several studies have attempted to understand the uncertainty associated with the use of different PBL depth definitions and have found the estimated
PBL depth to depend substantially on the method chosen. Vogelezang and Holtslag (1996) examined the PBL depth by defining it using both bulk and gradient Richardson numbers and found that the choice of Richardson number, the critical number chosen, and the inclusion of surface friction impacted the results. Seidel et al. (2010) tested seven different PBL depth definition methods on radiosonde profiles. Using a single data set, the estimated PBL depth was found to differ by up to several hundred meters. The use of different methods in their study also produced different seasonal variations. They concluded that it is necessary to compare different PBL depth estimates from different sources using the same method. In a later study, Seidel et al. (2012) recommended a bulk Richardson number based definition.

Numerous studies have also examined the impact of varying the observational platform in the estimation of PBL depth. For example, Nielsen-Gammon et al. (2008) analyzed mixing height estimates over Houston, Texas, USA from an airborne microwave temperature profiler, an airborne lidar, radiosondes, in situ aircraft, and wind profilers. They found generally good agreement, but this agreement was subject to spatial representativeness errors, and the lidar estimate was systematically higher than the microwave temperature profiler estimate. Helmis et al. (2012) compared two mesoscale models, a sodar-RASS (Radio Acoustic Sounding System), and a ceilometer. They found that reliable PBL depth estimates could be made using each approach only under certain meteorological conditions. Hu et al. (2010) compared three PBL schemes in a mesoscale model, finding that the local PBL scheme diagnosed a lower PBL depth when examining the turbulent kinetic energy profile than when estimating 
this depth using the potential temperature profile. Seibert et al. (2000) described multiple PBL depth estimation methods and concluded that the applicability of a PBL depth definition is dependent on the meteorological conditions and that different definitions can result in large differences in the estimated depth.

In the present study, seven different methods to compute the PBL depth were incorporated into the Goddard Earth Observation System (GEOS-5) atmospheric general circulation model (AGCM) (Rienecker et al., 2008; Molod et al., 2012) and compared using a single climate simulation. The seven methods are based on vertical profiles of the eddy diffusion coefficient for heat $\left(K_{\mathrm{h}}\right)$, the bulk $\left(R i_{\mathrm{b}}\right)$ and local $(R i)$ Richardson numbers, and the horizontal, shear-based component of the turbulent kinetic energy (TKE). In order to provide insight into implications on the regional and global climate scale, results were aggregated onto the Köppen-Geiger climate classes over land (Peel et al., 2007).

The purpose of this study is twofold. First, it analyzes differences among the PBL depth definitions evaluated diagnostically within the GEOS-5 AGCM. Results of this comparison will be used to develop a better state-dependent estimate of the turbulent length scale, which must be specified in the current model's turbulence parameterization. A second purpose of this study is to evaluate the influence of different processes, such as turbulence generated by shear and radiative interactions with cloud, on the PBL depth. The following section provides a model description and a description of the PBL depth diagnostics used. The third section presents results of the comparison and the final section contains the conclusions.

\section{Model and PBL diagnostics}

\subsection{GEOS-5 model description}

The GEOS-5 AGCM is a comprehensive model with many uses, including atmosphere-only simulations, atmospheric data assimilation operational analyses and reanalyses, and seasonal forecasting when coupled to an ocean model (Rienecker et al., 2008; Molod et al., 2012). An earlier version was used for the Modern-Era Retrospective Analysis for Research and Applications (MERRA) (Rienecker et al., 2011). The latitude-longitude hydrodynamical core of the GEOS-5 AGCM uses the finite volume dynamical core of Lin (2004) and the cubed sphere version is based on Putman and Lin (2007). The GEOS-5 AGCM includes moist physics with prognostic clouds (Bacmeister et al., 2006). The convective scheme is a modified version of the relaxed ArakawaSchubert of Moorthi and Suarez (1992), the shortwave radiation scheme is that of Chou and Suarez (1999), and Chou et al. (2001) describe the long-wave radiation scheme. The Catchment Land Surface Model is used to determine fluxes at the land/atmosphere interface (Koster et al., 2000) and the surface layer is determined as in Helfand and Schubert (1995). The model uses 72 vertical layers that transition from terrain following, near the surface, to pure pressure levels above $180 \mathrm{hPa}$.

Since details of the turbulence parameterization in the current version of the GEOS-5 AGCM (Rienecker et al., 2008; Molod et al., 2012) are relevant to the analysis of results of the current study, they are described here. The turbulence parameterization is based on the Lock et al. (2000) scheme, acting together with the Richardson number based scheme of Louis et al. (1982). The Lock scheme represents non-local mixing in unstable layers, either coupled to or decoupled from the surface. The parameterization computes the characteristics of rising or descending parcels of air ("plumes"), initiated due to surface heating or to cloud top cooling of boundary layer clouds. The GEOS-5 AGCM implementation includes moist heating in the calculation of buoyancy and a shear-dependent entrainment in the unstable surface parcel calculations. It is formulated using moist conserved variables, namely the liquid-frozen water potential temperature and the specific total water content, so that it can treat both dry and cloudy layers. The turbulent eddy diffusion coefficients are computed using a prescribed vertical structure, based on the height of the surface and radiative parcels or plumes.

The Louis scheme is a first-order local scheme, and the eddy diffusion coefficients are computed using Richardson number based stability functions for stable and unstable layers. The Louis scheme unstable layer stability functions require the specification of a turbulent length scale, which is formulated using a Blackadar-style (1962) interpolation between the height above the surface and a length scale based on the combined Lock and Louis schemes at the previous model time step. Many AGCMs specify the length scale a priori to a constant global value (e.g., Sandu et al., 2013). This estimate of the turbulent length scale was designed to provide a state-dependent estimate and to add "memory" to the turbulence parameterization. The eddy diffusion coefficients used for the AGCM turbulent diffusion are the larger of the Lock or Louis coefficients at any time step.

The simulation performed for this study uses C180 (approximately $1 / 2^{\circ}$ ) horizontal resolution on the cubed sphere grid. The simulation covers January 1990 through May 2013 and is initialized using MERRA analysis on 31 December 1989. The mean climate of this version of the GEOS-5 AGCM was shown in Molod et al. (2012) to compare well with a comprehensive set of observations.

\subsection{PBL depth diagnostics}

Seven different methods for determining the PBL depth are evaluated using the GEOS-5 AGCM based on several different output variables (Table 1). All methods diagnostically evaluate the same atmospheric profiles and all differences are related solely to the difference in definition of PBL depth. 
Table 1. Summary of PBL depth Methods.

\begin{tabular}{|c|c|c|}
\hline Method & Abbreviation & Description \\
\hline 1 & Kh: 2 threshold & Uses total $K_{\mathrm{h}}$ and a threshold of $2 \mathrm{~m}^{2} \mathrm{~s}^{-1}$ \\
\hline 2 & Kh: $10 \%$ threshold, rad & $\begin{array}{l}\text { Uses total } K_{\mathrm{h}} \text { and a threshold equal to } 10 \% \text { of the column } \\
\text { maximum, includes the radiative plume }\end{array}$ \\
\hline 3 & Kh: $10 \%$ threshold, no rad & $\begin{array}{l}\text { Uses total } K_{\mathrm{h}} \text { and a threshold equal to } 10 \% \text { of the column } \\
\text { maximum, does not include the radiative plume }\end{array}$ \\
\hline 4 & Bulk $R i$ & $\begin{array}{l}\text { Uses the bulk Richardson number described by Seidel et } \\
\text { al. (2012) and a critical value of } 0.25 \text {; used to estimate } \\
\text { PBL depth from radiosonde profiles }\end{array}$ \\
\hline 5 & $R i_{\text {crit }}=0.2$ & Uses a local Richardson number and a critical value of 0.2 \\
\hline 6 & $R i_{\text {crit }}=0$ & Uses a local Richardson number and a critical value of 0 \\
\hline 7 & Horizontal TKE & $\begin{array}{l}\text { Uses the diagnosed horizontal turbulent kinetic energy and } \\
\text { a threshold of } 10 \% \text { of the column maximum }\end{array}$ \\
\hline
\end{tabular}

The first method (Method 1) is based on the total eddy diffusion coefficient of heat $\left(K_{\mathrm{h}}\right)$ and uses a threshold value of $2 \mathrm{~m}^{2} \mathrm{~s}^{-1}$. This method estimates the PBL depth as the model level under which $K_{\mathrm{h}}$ falls below this threshold. No vertical interpolation is used for this method and the estimated height is the model level edge. This method is the PBL definition used to determine the PBL depth in MERRA, and it is also used in the current GEOS-5 AGCM as part of the statedependent estimate of the turbulent length scale. The evaluation of this method is one of the goals of the present study because any error in PBL depth shown to be associated with the use of this method may adversely influence the model's simulated climate.

Methods 2 and 3 use a variable $K_{\mathrm{h}}$ threshold that depends on the atmospheric profile rather than a constant value. These methods use a threshold of $10 \%$ of the column maximum and linearly interpolate between levels to determine the PBL depth. Method 2 uses the total $K_{\mathrm{h}}$ and Method 3 uses the surface buoyancy driven eddy diffusion coefficient (neglecting the contribution from the radiative plume). Method 3 therefore neglects the direct influence of clouds, and comparisons between this method and Method 2 isolate the role of the turbulence due to negative buoyancy at cloud top associated with cloud-topped boundary layers.

The PBL depth definition used by Seidel et al. (2012) is used as Method 4. They selected this method because of its applicability to radiosondes and model simulations and its suitability for convectively unstable and stable boundary layers. This method uses a bulk Richardson number $\left(R i_{\mathrm{b}}\right)$ given by

$R i_{\mathrm{b}}(z)=\frac{\left(\frac{g}{\theta_{\mathrm{vs}}}\right)\left(\theta_{\mathrm{v} z}-\theta_{\mathrm{vs}}\right)\left(z-z_{\mathrm{s}}\right)}{u_{z}^{2}+v_{z}^{2}}$,

where $g$ is the gravitational acceleration, $\theta_{\mathrm{v}}$ is the virtual potential temperature, $u$ and $v$ are the horizontal wind components, and $z$ is height above the ground. The virtual potential temperature, by definition, is based on water vapor but not condensate. The subscript $s$ denotes the surface. The surface winds are assumed to be zero. This bulk Richardson number is evaluated based on differences between the surface and successively higher levels, assuming that the surface layer is unstable, and the PBL top is identified as the level at which $R i_{\mathrm{b}}$ exceeds a critical value of 0.25 . The PBL height is found by linearly interpolating between model levels.

Methods 5 and 6 use different versions of the bulk Richardson number evaluated between two consecutive levels (rather than between the surface and the current height) that we term the "local" Richardson number. This local Richardson number $(R i)$ is calculated as

$\operatorname{Ri}(z)=\frac{\left(\frac{g}{\theta_{\mathrm{v}}}\right)\left(\theta_{\mathrm{v} z 1}-\theta_{\mathrm{v} z 2}\right)\left(z_{1}-z_{2}\right)}{\left(u_{z 1}-u_{z 2}\right)^{2}+\left(v_{z 1}-v_{z 2}\right)^{2}}$.

Here $z_{1}$ and $z_{2}$ represent the heights of the model levels above and below the current level, respectively, and $\theta_{\mathrm{v}}$ without a subscript number is the average virtual potential temperature between heights $z_{1}$ and $z_{2}$. The PBL top is found by assuming that the surface is unstable and linearly interpolating between the model levels where the critical value is crossed. We test two critical Richardson numbers to determine the sensitivity of the method to the critical value chosen. Method 5 uses a critical local Richardson number value of 0.2 and Method 6 uses a critical local Richardson number value of 0.0 . A critical value of 0.0 was chosen because in the Louis scheme of the GEOS-5 AGCM, Richardson number values less than 0.0 are assumed to represent an unstable atmosphere. The Richardson number methods do not directly consider the presence or absence of low-level clouds (Seidel et al., 2012).

We use a scaling approximation of TKE to estimate the PBL depth in Method 7. The Lock scheme is not very sensitive to boundary layer shear so we chose a scaling based only on shear sources of TKE to isolate the shear contribution. The top of the PBL is taken to be the height at which the shear-based TKE falls below a threshold value of $10 \%$ 


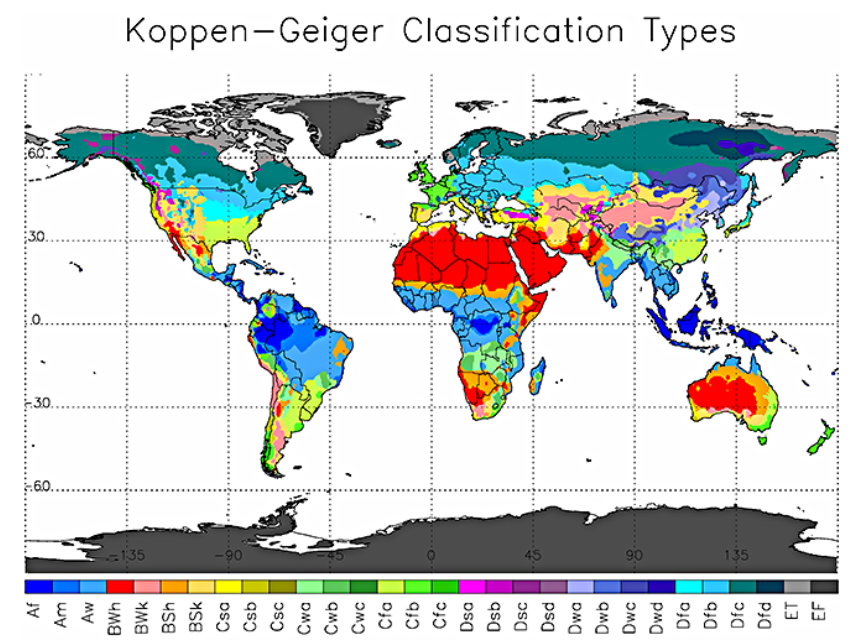

Figure 1. Köppen-Geiger climate classes as determined by Peel et al. (2007) re-gridded to $0.5^{\circ} \times 0.5^{\circ}$. The first letter indicates the broad climate class as tropical (A), arid (B), temperate (C), cold (D), and polar (E). Please see Table 1 of Peel et al. (2007) for a full description of the climate classifications.

of the column maximum, vertically interpolating between model levels. The horizontal TKE method should be more sensitive to the wind profile and seasonal changes to it than the other methods, and the daytime PBL heights based on this method should be expected to be lower than PBL height estimates based on static stability.

Due to the vertical resolution of the GEOS-5 AGCM, the minimum PBL depth for each of the methods coincides with the top of the lowest model layer at about $150 \mathrm{~m}$ above the surface.

\subsection{Climate classes}

The computed PBL depths are aggregated by season onto the Köppen-Geiger climate classes (Fig. 1). The KöppenGeiger climate classes have been used to group rivers worldwide for comparisons of runoff characteristics (McMahon et al., 1992; Peel et al., 2004). Molod and Salmun (2002) successfully used this aggregation in their study investigating the implications of using different land surface modeling approaches. Their study aggregated results such as canopy temperature, soil moisture, and turbulent fluxes and they were able to use these results to make generalizations that extend to broad climate regions relevant for global models. Aggregation onto these climate classes is a way to characterize similar remote regions and apply findings globally.

Peel et al. (2007) recently updated the Köppen-Geiger climate classification, taking advantage of advances in data availability and computing power. They did this by using monthly mean precipitation and temperature data from over 4000 stations (plus additional data from stations reporting only temperature or only precipitation) and interpolating be- tween them using a two-dimensional thin-plate spline with tension. The final map is generated on a $0.1^{\circ} \times 0.1^{\circ}$ grid. The highest station density is in the USA, southern Canada, northeast Brazil, Europe, India, Japan, and eastern Australia while the lowest station data densities are located in desert, polar, and some tropical regions.

Peel et al. (2007) used the same classes as the original classification system, but with an updated distinction criterion between the temperate and cold climate classes. The classification consists of five main climate types: tropical (A), arid (B), temperate (C), cold (D), and polar (E) with further divisions based on seasonal variations in temperature and precipitation. They define summer (winter) as the warmer (cooler) six month period of October through March (April through September). In this paper, we refer to summer (winter) as June through August in the Northern (Southern) Hemisphere and December through February in the Southern (Northern) Hemisphere. Peel et al. (2007) provide a full description of the climate classifications including details on how they were determined. The broad climate types, defined over land, are relatively insensitive to temperature trends, including those from global climate change (Triantafyllou and Tsonis, 1994; Peel et al., 2007) and are intended to represent long term mean climate conditions and not year-to-year variability.

\subsection{Radiosonde-based estimates}

Seidel et al. (2012) provided radiosonde-based climatological PBL depths estimated using the bulk Richardson number method (Method 4) as part of their supplemental material. They estimated the PBL depth from the Integrated Global Radiosonde Archive (IGRA) (Durre and Yin, 2008) over Europe and the United States for the period 1981-2005. After evaluating several sources of uncertainty, they found that the bulk Richardson number method was suitable for application to large radiosonde and climate model data sets and was sensitive to climatological features. Seidel et al. (2012) provide a full description of this data set.

These observed depths are aggregated by climate class and local time, similarly to the model data. Although the radiosonde-based PBL depths and those estimated by the model are from different time periods, they both represent climatological conditions and so provide an estimate of the deficiencies in the model simulated diurnal cycle.

\section{Results}

This section describes the results of the comparison of the different PBL depth estimates aggregated to the KöppenGeiger climate classes. Section 3.1 provides a quantitative description of the variability within climate classes, explains some of the reasons for this variability, and justifies the reliance on the climate class aggregated analysis. The following subsections show the general PBL depth response to 
the different definitions, describe in detail the results from classes that deviate from this behavior, and examine in detail reasons for the difference between the PBL depths estimated using the $K_{\mathrm{h}}$ and bulk Richardson number methods. The final subsection reports on the PBL height differences related to the cloud-activated Lock scheme's radiative plume.

\subsection{Variability within climate classes}

The Köppen-Geiger classification does not explicitly take into account some aspects of the climate system relevant to boundary layer processes such as intensity of precipitation, elevation, terrain, and overlying subsidence. The aggregation of PBL height onto climate classes is therefore useful for examining the behavior of the different estimates globally, but differences in behavior within climate classes are neglected by definition. Figure 2 shows seasonal mean PBL depths computed with Method 1. The error bars indicate the amount of spatial variability within each climate class. This variability can be characterized in terms of four broad classifications: tropical, arid, temperate, and cold, and examples characteristic of results from each are shown here.

Figure 2a shows the annual mean diurnal cycle of PBL depth and standard deviation in the tropical rainforest (Af). The annual mean is shown because seasons based on temperature are not distinct near the equator. Variability is fairly uniform through the diurnal cycle with the standard deviation being about $39 \%$ of the mean PBL depth. This climate class will be discussed in greater detail below. Figure $2 b$ shows the summer mean diurnal cycle of PBL depth and standard deviation for the arid, hot desert. This climate class also produces fairly uniform standard deviations through the diurnal cycle with a mean ratio of standard deviation to PBL depth of about $39 \%$. Figure $2 \mathrm{c}$ shows the summer mean diurnal cycle for the temperate, dry winter, hot summer climate class. In this class, the variability has a diurnal cycle in which the standard deviation is smallest at night and larger during the day. The mean standard deviation is about $31 \%$ of the PBL depth. However, during the dry winter, the variability is more uniform (not shown), similar to the dry climate class represented in Fig. 2b. Figure 2d shows the summer mean diurnal cycle in the cold, warm summer, no dry season climate class. For this class, the standard deviation has lower variability at night than during the day and the standard deviation is about $31 \%$ of the PBL depth. In addition to variations of diagnosed PBL depth within climate classes, there are also variations in the functional dependence of PBL depth on atmospheric state or fluxes. The details of two examples of variability within climate classes are presented here.

Spatial maps in Fig. 3 show the relationship between PBL depth and surface temperature in the Saharan and Arabian deserts. Figure 3a shows that, in JJA (June-August), the PBLs over the coastal regions of the Saharan and Arabian deserts are more than a kilometer shallower than the PBLs found further inland. This behavior reflects the variability of
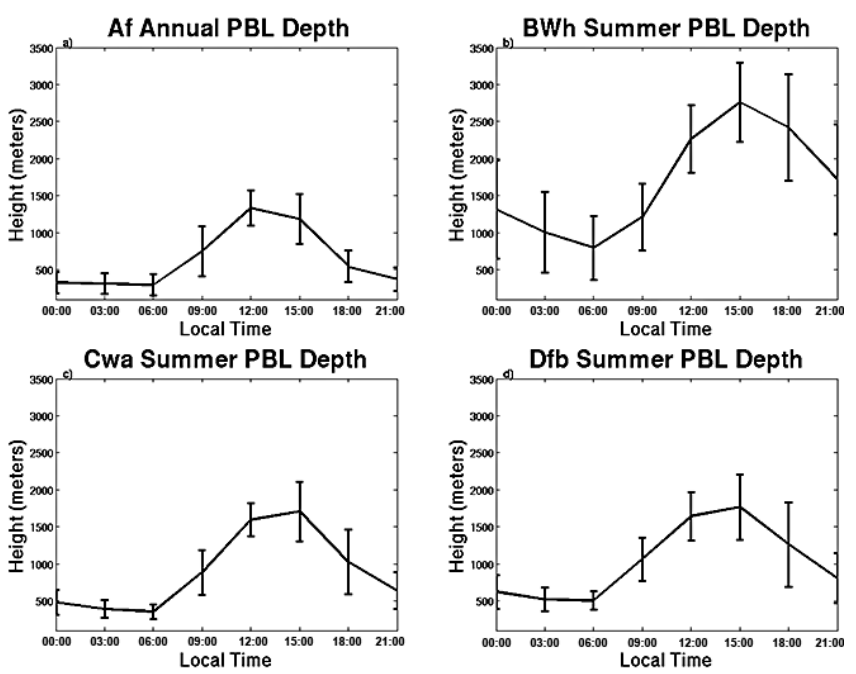

Figure 2. Diurnal cycle of annual mean PBL depth for the tropical forest (Af, a) and summer seasonal mean diurnal cycle of PBL depth for arid, hot desert (BWh, b); temperate, dry winter, hot summer (Cwa, c); and cold, warm summer, no dry season (Dfb, d) climate classes estimated using Method 1. Error bars indicate the standard deviation computed globally using the time mean PBL depth within the climate classes.

the surface temperature within the BWh climate class. A spatial map of the JJA skin temperature (Fig. 3b) shows a similar pattern as the PBL depth. A scatter diagram (not shown) of PBL heights and skin temperature revealed that $>60 \%$ of PBL height variability is explained by skin temperature. However, some variability exists that is not explained by temperature. For instance, over the western part of the Arabian Desert, the PBL depths are greater than would be expected based on temperature due to upslope winds over the higher topography opposing the overlying subsidence.

The second example of intra-class variability is illustrated in Fig. 4, which shows the relationship between PBL depth and $10 \mathrm{~m}$ temperature for the tropical rainforest climate class (Af). In this climate class, and in the other tropical climate classes, there is a shift in the relationship between PBL depth and $10 \mathrm{~m}$ temperature near $302 \mathrm{~K}$. This temperature is near the wilting point for broadleaf evergreen vegetation, the dominant vegetation type in the tropics. At temperatures above the wilting point, the vegetation experiences moisture stress, thus severely limiting transpiration and more of the net radiation at the surface is lost as sensible heat flux. Since sensible heat is much more efficient at growing the PBL than latent heat (Ek and Holtslag, 2004), the PBL depth increases rapidly with temperature in this drier regime. In the regime below the wilting point, transpiration increases with temperature and proceeds with little resistance, wetting the lower atmosphere. In this wetter regime, PBL depth decreases with temperature.

These different regimes and sensitivities of PBL depth to different variables must be kept in mind when examining 

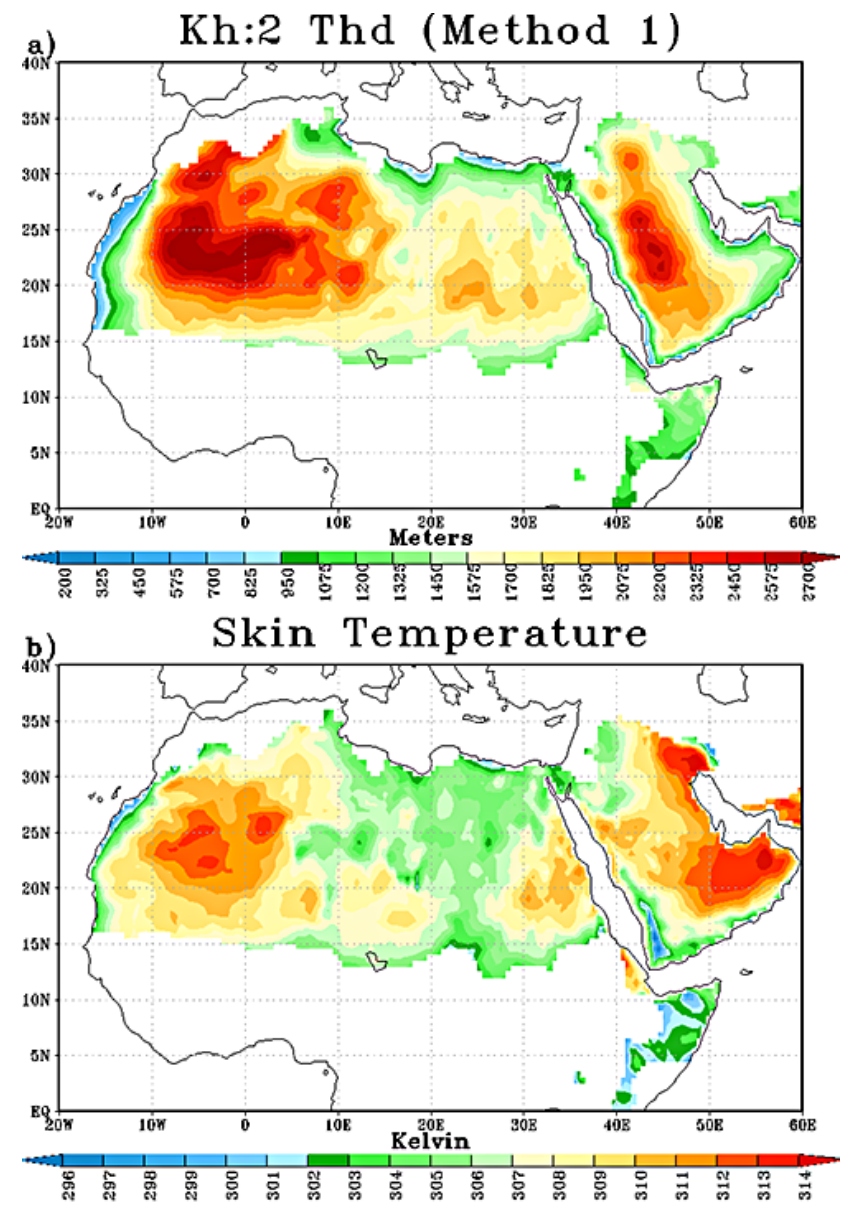

Figure 3. PBL depth (calculated using Method 1) over climate class BWh (hot, arid desert) (a) and surface skin temperature (b) in JJA.

climatological boundary layer depth. Although the KöppenGeiger climate classes are useful for organizing land regions in order to make generalizations and simplify the analysis, they do not capture all the conditions relevant to boundary layer processes. There will therefore be geographical differences within each climate class that will not be captured by this analysis.

\subsection{General method behavior}

When aggregated by climate class, the PBL depth definitions produce similar results for most classes and seasons. In general, both local Richardson number methods (Methods 5 and 6) estimate PBL depths that are lower than the other methods' estimates throughout the diurnal cycle. The bulk (Method 4) Richardson number method estimates shallower nocturnal PBLs than the $K_{\mathrm{h}}$ methods (Methods 1, 2, and 3) and wintertime PBLs estimated by the TKE method (Method 7) are generally deeper than estimated by the other methods.

The focus of the discussion here is on illustrations of the significant differences based on the behavior of PBL depths

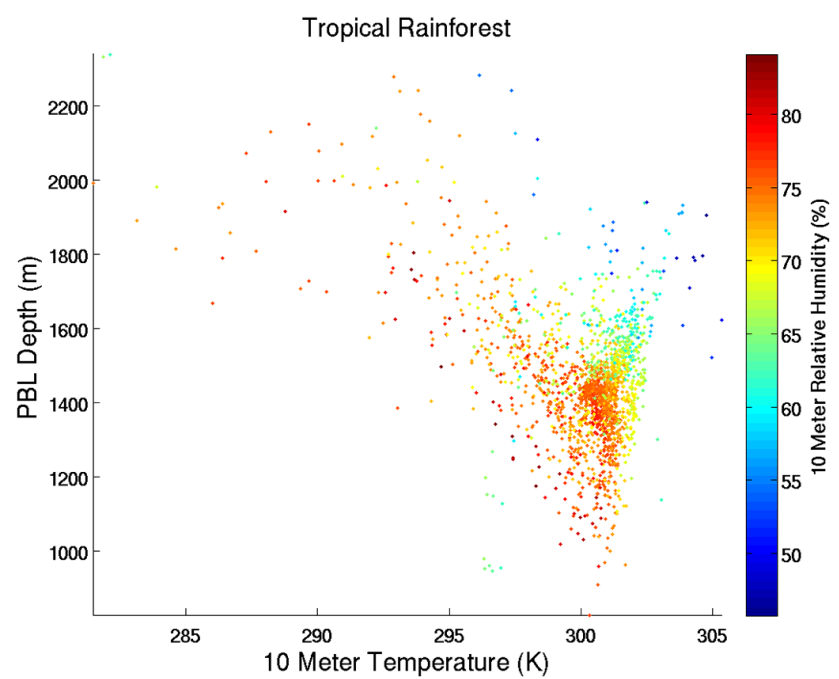

Figure 4. Scatter plot of PBL depth vs. $10 \mathrm{~m}$ temperature for the tropical rainforest climate class in the annual mean. Each dot represents the mean midday PBL depth and $10 \mathrm{~m}$ temperature. The PBL depth is defined using the $K_{\mathrm{h}}$ definition (Method 1) in the GEOS-5 AGCM. The colors highlight the $10 \mathrm{~m}$ relative humidity.

from representative climate classes. Figure 5 shows the seasonal mean diurnal cycle for the cold climate class with warm summers and no dry season (Dfb; during summer Fig. 5a and winter Fig. 5c) and for the hot, arid desert class (BWh; during summer Fig. 5b and winter Fig. 5d). The vertical bars are three standard deviations in either direction, where the standard deviation is computed as the deviation from the seasonal mean PBL depth calculated for each climate class and each year, and therefore represents temporal variability.

For these climate classes, the PBL depths estimated by the $K_{\mathrm{h}}$ methods using a $10 \%$ threshold (Method 2, red and Method 3, red dashed) are quite similar, as expected in climate classes in which the atmosphere is nearly insensitive to the ability of the model to generate turbulence in the radiative plume. The PBL depths estimated using the bulk Richardson number (Method 4, green), and the three $K_{\mathrm{h}}$ methods (Methods 1, black, Method 2, red, and Method 3, red dashed) give comparable midday results. Although the horizontal TKE definition (Method 7, blue) gives similar midday results as the $K_{\mathrm{h}}$ and bulk Richardson number methods under most conditions, during the winter the horizontal TKE method often gives mean midday PBL depths that are $100 \mathrm{~m}$ higher than the other methods (Fig. 5c) associated with the greater wintertime wind shear in the winter storm tracks within the Dfb climate class, and are $500 \mathrm{~m}$ higher in the winter (Fig. 5d) due to the wind shear aloft in the desert class.

Figure 5 also shows that the methods based on the local Richardson number (Methods 5 and 6) estimate PBL depths that are several hundred meters lower at midday than PBL depths estimated using the other methods. This is the case for all the climate classes studied here. This method does 

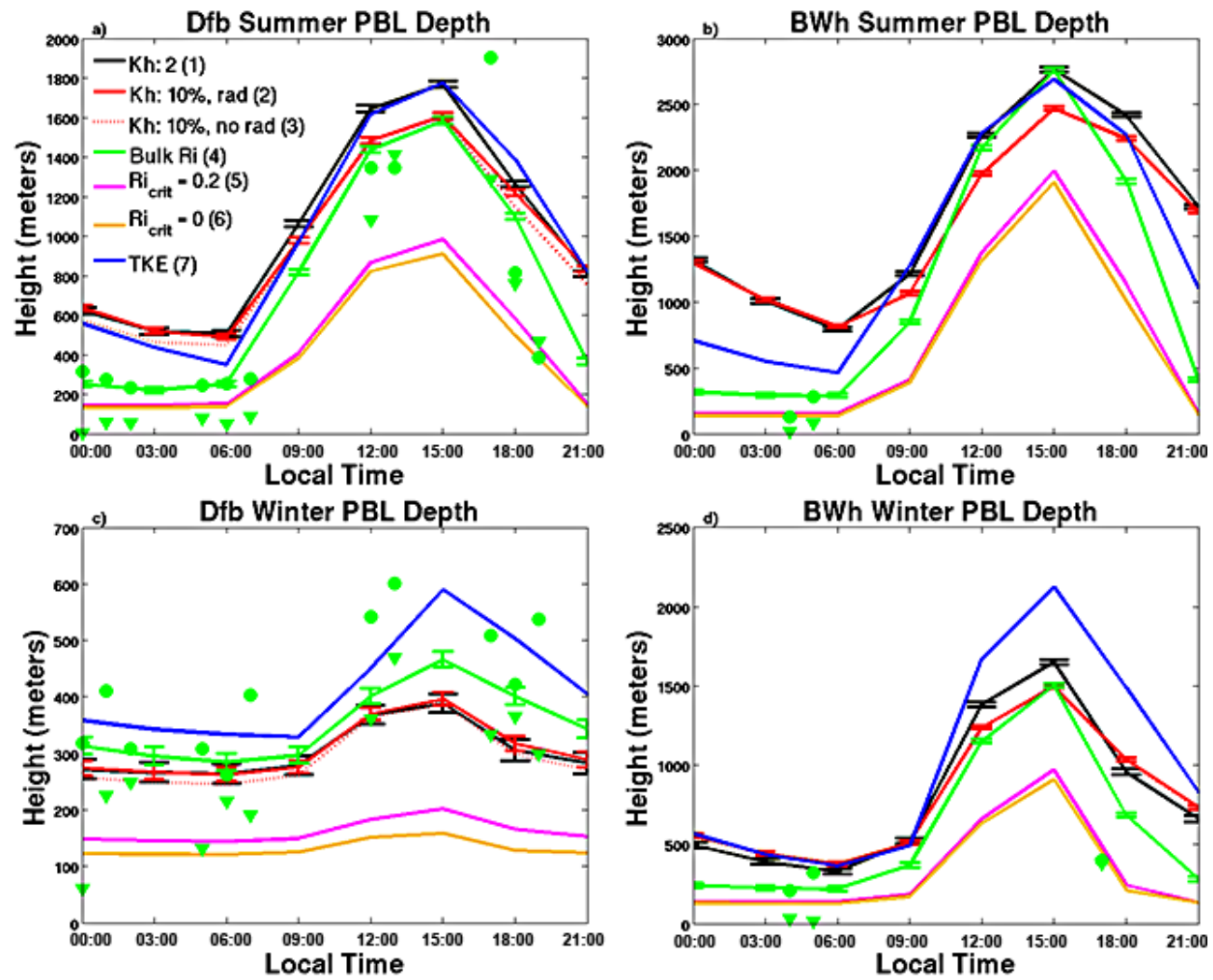

Figure 5. Seasonal mean diurnal cycle of PBL depth for climate classes Dfb (Cold with warm summers and no dry season, during summer and winter, $\mathbf{a}$ and $\mathbf{c}$ ) and BWh (hot, arid desert, during summer and winter, b and d) using seven different methods for estimating the PBL depth. The error bars represent three standard deviations for methods 1, 2, and 4. The green triangles indicate the observed PBL depth from the IGRA data set (Method 4) and the green circles represent the modeled PBL depth (Method 4) at the observation locations.

not depend greatly on the critical value chosen as the differences between PBL depths estimated using a critical value of zero are only slightly lower than those estimated using a critical value of 0.2 . For both climate classes, the mean difference between Methods 5 and 6 are larger during summer than during winter. The percentage difference for the Dfb climate class during winter is about $20 \%$ while during summer and for the BWh climate class in both seasons it is around $6-8 \%$. Through the diurnal cycle, mean differences are maximal during the afternoon for all four cases. The low PBL depths estimated by the local Richardson number methods make these methods impractical for AGCM-based PBL depth estimates.

Planetary boundary layers based on Richardson number methods (local and bulk) are lower at night than those based on $K_{\mathrm{h}}$ or TKE for most classes in summer and winter. This has implications for estimating the shallow nocturnal boundary layer. The depth of this layer has been shown to be relevant for constituent transport since surface-emitted pollutants are generally mixed within it (e.g., Denning et al., 1995; Jacob et al., 1997; Lin and McElroy, 2010). For instance, over climate class BWh (Fig. 5b), the bulk Richardson number nocturnal PBL is well under $500 \mathrm{~m}$ while the $K_{\mathrm{h}}$ methods estimate a PBL depth between 1000 and $1500 \mathrm{~m}$ at night during the summer. The exceptions to this pattern occur in cold winter climates where PBL depths are low for all methods (Fig. 5c). Figure 6 shows example day and nighttime profiles from a point in the Dfb climate class in the summer. In these profiles, the surface bulk Richardson number (Fig. 6b) is slightly unstable during the day and becomes stable at night. The PBL estimated using this method responds to the change in atmospheric stability with a depth over $1500 \mathrm{~m}$ during the day and lower at night. However, the $K_{\mathrm{h}}$ profiles predict a different response with nighttime PBL depth estimates using Methods 1 and 2 similar to the daytime estimates due to an elevated diffusion layer at night.

The BWh climate class (Fig. 5b, d) contains radiosonde observations of the nocturnal boundary layer and during the evening transition from a convective to a stable boundary. The observations are from the American southwest (one coastal station omitted); each represents a single radiosonde station, and do not sample the large desert regions in Africa and Australia, but they provide some insight into how well the model simulates the nocturnal PBL. The observed boundary layers are lower than those simulated by the model by approximately 100 to $300 \mathrm{~m}$. The radiosonde-based estimates 

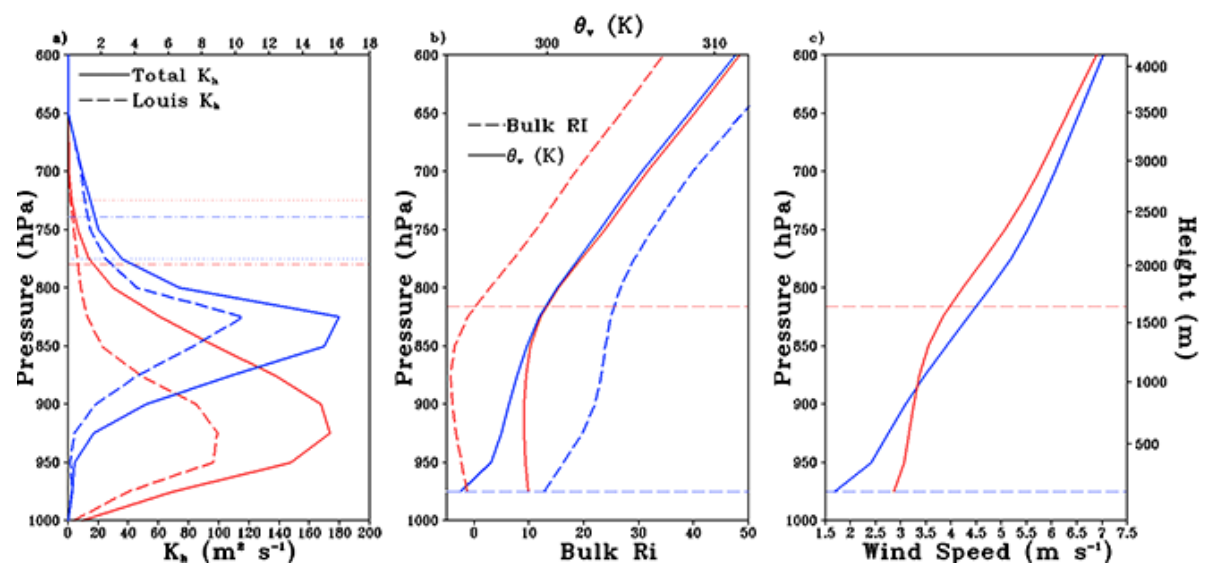

Figure 6. Summer mean vertical profile of total and Louis eddy diffusivities (a), bulk Richardson number and virtual potential temperature (b), and wind speed (c) in the Dfb climate class $\left(50^{\circ} \mathrm{N}, 30^{\circ} \mathrm{E}\right)$. The horizontal lines represent the PBL depth (Method 1, dots, a; Method 2, dot dash $\mathbf{a}$; and Method 4 dashed, b and $\mathbf{c}$ ). Red indicates daytime and blue indicates nighttime. The horizontal scale at the top of (a) is for the nighttime profiles.

sample the PBL depth over the Dfb climate class (Fig. 5a and c) well because much of eastern Europe and the northern United States belong to this climate class. Each observed point represents between 1 and 14 stations. Similar to the model behavior in the desert climate class, the model estimates higher nocturnal boundary layer depths than the radiosonde-based estimates during summer (mean difference of $210 \mathrm{~m}$ ) and winter (mean difference of $155 \mathrm{~m}$ ). During the day, the mean difference between the model and radiosonde estimates during both seasons is more variable, with differences ranging from approximately $10 \mathrm{~m}$ up to $150 \mathrm{~m}$, but model estimates are generally lower.

\subsection{Bulk Richardson vs. $K_{\mathrm{h}}$ methods}

The bulk Richardson number and $K_{\mathrm{h}}$ methods generally give similar midday results, but under warm, wet conditions the estimated daily maximum PBL depth found using the bulk Richardson number method tends to be lower than the $K_{\mathrm{h}}$ methods (Fig. 7). An example of this behavior is shown by examining the tropical rainforest climate class, but this occurs in the other tropical climate classes during their rainy seasons and for temperate climate classes when it is both warm and the climatological precipitation is high (not shown). This difference in estimated PBL depth means that the bulk Richardson number exceeds its critical value at a level below where $K_{\mathrm{h}}$ decreases to its threshold. This implies either a virtual potential temperature inversion or a change in the wind speed within a layer of relatively high $K_{\mathrm{h}}$.

Figure 8 shows the annual mean vertical profiles during the day and at night of total $K_{\mathrm{h}}$ and $K_{\mathrm{h}}$ from the Louis parameterization (Fig. 8a), the bulk Richardson number and virtual potential temperature (Fig. 8b), and the wind speed (Fig. 8c) from a typical location within the Amazonian rainforest. The bulk Richardson number method detects a day-

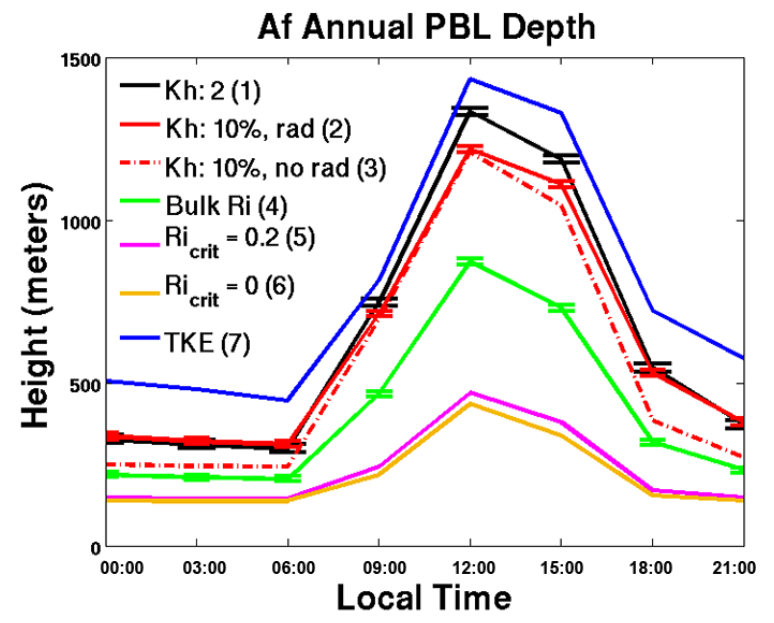

Figure 7. Annual mean diurnal cycle of PBL depth for climate class Af (tropical rainforest) using seven different methods for estimating the PBL depth; no radiosonde observations were present for this climate class. The error bars represent three standard deviations for methods 1,2 , and 4 .

time stable layer below where $K_{\mathrm{h}}$ decreases to its threshold. This is due to the presence of a small inversion in the virtual potential temperature profile.

This behavior could occur under several different meteorological conditions. There could be a turbulent layer aloft that is not fully decoupled from the surface layer that is being detected by the $K_{\mathrm{h}}$ methods but not by the bulk Richardson number method. Since the Louis turbulence parameterization is dependent upon the local Richardson number $(R i)$, it contains some information about the vertical profile of temperature and shear. While this is a different form of the Richardson number than the one used in the bulk Richardson number method, the Louis scheme can provide information about 

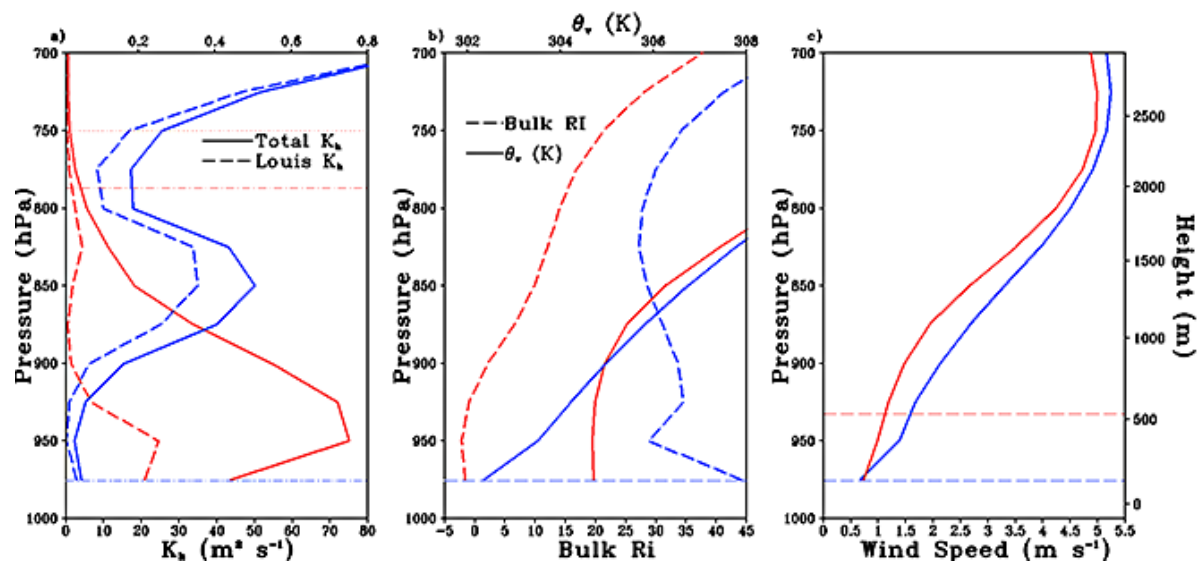

Figure 8. Annual mean vertical profile of total and Louis eddy diffusivities (a), bulk Richardson number and virtual potential temperature (b), and wind speed $(\mathbf{c})$ in the Amazonian rainforest $\left(0^{\circ} \mathrm{N}, 70^{\circ} \mathrm{W}\right)$. The horizontal lines represent the PBL depth (Method 1, dots, a; Method 2, dot dash $\mathbf{a}$; and Method 4 dashed, $\mathbf{b}$ and $\mathbf{c}$ ). Red indicates daytime and blue indicates nighttime. The horizontal scale at the top of Fig. 8a is for the nighttime profiles. Methods 1 and 2 estimate the same nighttime PBL depth.

what to expect from the bulk Richardson number method. If the $K_{\mathrm{h}}$ predicted by the Louis scheme alone (Fig. 8a) has its maximum in a shallow layer low to the ground before decreasing, it can be expected that the PBL depth found using the bulk Richardson number might also be low. If the Lock scheme is strongly active aloft due to entrainment or radiation, the $K_{\mathrm{h}}$ methods will detect a deeper PBL.

\subsection{Impact of the radiative plume}

In order to examine the impact of radiative cooling at cloud top, the $K_{\mathrm{h}}$ method using a threshold of $10 \%$ of the column maximum was compared diagnostically with (Method 2) and without (Method 3) the contribution from the radiative plume. The difference between these two methods is useful for understanding the influence of clouds on PBL depth in the GEOS-5 AGCM. Figure 9 shows the PBL depth difference between the two methods for JJA. At all locations, the PBL depth estimated using the radiative plume is at least as large as that without the radiative plume. The largest differences occur over land in the summer hemisphere and in the Tropics during the evening transition. This result also holds for December, January, and February (DJF) (not shown). The timing of the largest differences (evening) is due to the sensitivity of the radiative plume to cloud top. At night, the total $K_{\mathrm{h}}$ decreases due to the lack of incoming solar radiation, but the diffusivity associated with the radiative plume decreases proportionally less since cloud do not dissipate during the evening transition. The radiative plume eddy diffusion coefficient thus becomes proportionally more important at night and the PBL depth remains greater. The nonradiative method PBL heights are therefore lower at night, consistent with expectations.

Although this study focuses on the sensitivity of simulated PBL depths over land, there are persistent regions of rela- tively large radiative plume impact over the oceans as well, occurring around $30^{\circ} \mathrm{N}$ and $45^{\circ} \mathrm{S}$. This is due in part to the behavior of the microphysics parameterization in the GEOS5 AGCM and perhaps to the nature of low level clouds in these regions. The GEOS-5 AGCM uses an empirical estimate of cloud particle radii based on temperature, pressure, and wind. The large differences over oceans are located in regions where the boundary layer clouds contain condensate with small prescribed effective radii and are thus more radiatively active. Since the radiative plume is more active in these locations, PBL depths based on methods sensitive to its impact are greater than depths computed using methods that ignore it.

\section{Conclusions}

Although the PBL depth is important for AGCMs and its realistic simulation has implications for climate and weather prediction, observations are limited and no consensus on a definition exists. Complicating things further, under certain conditions, different definitions can give significantly different results. This study examines this issue by evaluating the PBL depth using seven different diagnostic methods so that all differences can be attributed directly to the definition. Results were aggregated to Köppen-Geiger climate classes in order to make broad generalizations and simplify the analysis on a global scale. Intra-class variability was shown to be important, but did not impact the ability to make classdependent characterizations.

Under most conditions, the bulk Richardson number, eddy diffusion coefficient, and horizontal TKE methods give similar midday results over land. The horizontal TKE definition is more sensitive to shear and thus winter storms and so estimates greater midday PBL depths during the winter season. 


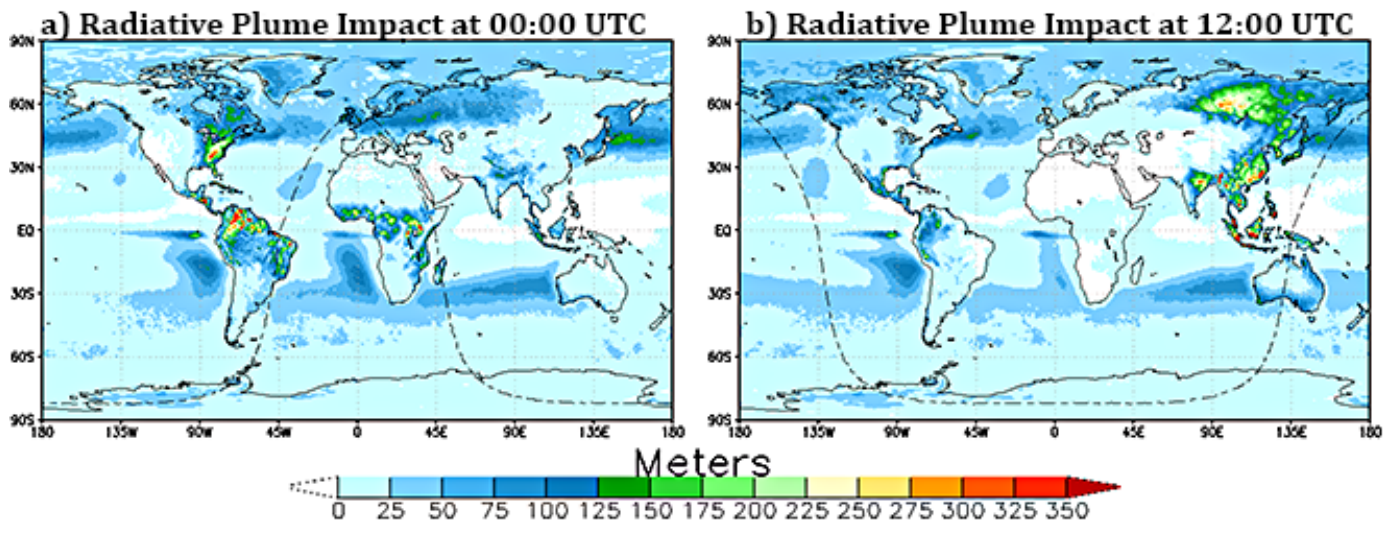

Figure 9. PBL depth response to radiative plumes during JJA at 00:00 (a) and 12:00 (b) UTC. The figure shows the $K_{\mathrm{h}}$ method using a $10 \%$ of the column maximum threshold including the radiative plume (Method 2) minus the same method, but without the radiative plume (Method 3). The dashed line is the shortwave radiation zero contour line.

Under warm, moist conditions, the bulk Richardson number method estimates PBL depths that are lower than those estimated by the $K_{\mathrm{h}}$ methods. This indicates that the bulk Richardson number is exceeding its threshold value below where $K_{\mathrm{h}}$ decreases to its threshold.

The impact of long-wave cooling from clouds on PBL depth was found to have its strongest effect over land during the evening transition. This was due to the persistence of cloud cover through the diurnal cycle. Additionally, regions of influence were found in the marine boundary layer related to the larger radiative impact in these regions.

The local Richardson number methods are relatively insensitive to the critical number used and estimate PBL depths several hundred meters lower than the other methods. These local Richardson number methods were therefore found to be inappropriate for use in an AGCM, probably due to the relatively coarse vertical resolution. The PBL depths found using the local and bulk Richardson number methods are generally lower at night than the PBL depth diagnosed using $K_{\mathrm{h}}$ and TKE methods. We speculate that this result is due to the choice of $K_{\mathrm{h}}$ threshold and that this threshold is more applicable to daytime convective boundary layers than to nocturnal PBLs.

The bulk Richardson number method (Method 4) provides the best match with radiosonde-based estimates, as expected, and also provides the most credible diurnal cycle, due in great part to its capture of low nocturnal boundary layer heights. It is therefore the method recommended for use in estimating the AGCM turbulent length scale. Future work will include incorporating the PBL depth estimated using the various methods into the calculation of the turbulent length scale in the GEOS-5 AGCM. Through this length scale, the PBL depth is allowed to modify vertical mixing and tracer transport and the implications for air quality and carbon inversion studies will be analyzed.
Acknowledgements. Computing was supported by the NASA Center for Climate Simulation. The research was supported by National Aeronautics and Space Administration grant NNG11HP16A.

Edited by: C. Gerbig

\section{References}

Bacmeister, J. T., Suarez, M. J., and Robertson, F. R.: Rain Reevaporation, Boundary Layer-Convection Interactions, and Pacific Rainfall Patterns in an AGCM, J. Atmos. Sci., 63, 3383-3403, doi:10.1175/jas3791.1, 2006.

Blackadar, A. K.: The vertical distribution of wind and turbulent exchange in a neutral atmosphere, J. Geophys. Res., 67, 30953102, doi:10.1029/JZ067i008p03095, 1962.

Chou, M.-D. and Suarez, M. J.: A solar radiation parameterization for atmospheric studies, Technical Report Series on Global Modeling and Data Assimilation, 40 pp., available at: http://gmao.gsfc.nasa.gov/pubs/docs/Chou136.pdf (last access: 4 March 2014), 1999.

Chou, M.-D., Suarez, M. J., Liang, X.-Z., and Yan, M. M.-H.: A thermal infrared radiation parameterization for atmospheric studies, Technical Report Series on Global Modeling and Data Assimilation, 56 pp., available at: http://gmao.gsfc.nasa.gov/pubs/ tm/docs/Chou137.pdf (last access: 4 March 2014), 2001.

Denning, A. S., Fung, I. Y., and Randall, D.: Latitudinal gradient of atmospheric $\mathrm{CO}_{2}$ due to seasonal exchange with land biota, Nature, 376, 240-243, 1995.

Durre, I. and Yin, X.: Enhanced Radiosonde Data For Studies of Vertical Structure, B. Am. Meteorol. Soc., 89, 1257-1262, doi:10.1175/2008bams2603.1, 2008.

Ek, M. B. and Holtslag, A. A. M.: Influence of Soil Moisture on Boundary Layer Cloud Development, J. Hydrometeorol., 5, 8699, doi:10.1175/1525-7541(2004)005<0086:iosmob>2.0.co;2, 2004.

Helfand, H. M. and Schubert, S. D.: Climatology of the Simulated Great Plains Low-Level Jet and Its Contribution to the Continental Moisture Budget of the United States, J. Climate, 8, 784-806, doi:10.1175/1520-0442(1995)008<0784:cotsgp>2.0.co;2, 1995. 
Helmis, C. G., Sgourous, G., Tombrou, M., Schäfer, K., Münkel, C., Bossioli, E., and Dandou, A.: A comparative study and evaluation of mixing-height estimation based on sodar-RASS, ceilometer data and numerical model simulations, Bound.-Lay. Meteorol., 145, 507-526, doi:10.1007/s10546-012-9743-4, 2012.

$\mathrm{Hu}$, X.-M. Nielsen-Gammon, J. W., and Zhang, F.: Evaluation of three planetary boundary layer schemes in the WRF model, J. Appl. Meteorol. Clim., 49, 1831-1844, doi:10.1175/2010JAMC2432.1, 2010.

Jacob, D. J., Prather, M. J., Rasch, P. J., Shia, R.-L., Balkanski, Y. J., Beagley, S. R., Bergmann, D. J., Blackshear, W. T., Brown, M., Chiba, M., Chipperfield, M. P., de Grandpré, J., Dignon, J. E., Feichter, J., Genthon, C., Grose, W. L., Kasibhatla, P. S., Köhler, I., Kritz, M. A., Law, K., Penner, J. E., Ramonet, M., Reeves, C. E., Rotman, D. A., Stockwell, D. Z. , Van Velthoven, P. F. J., Verver, G., Wild, O., Yang, H., and Zimmermann, P.: Evaluation and intercomparison of global atmospheric transport models using ${ }^{222} \mathrm{Rn}$ and other short-lived tracers, J. Geophys. Res., 102, 5953-5970, doi:10.1029/96JD02955, 1997.

Koster, R. D., Suarez, M. J., Ducharne, A., Stieglitz, M., and Kumar, P.: A catchment-based approach to modeling land surface processes in a general circulation model: 1 . Model structure, J. Geophys. Res.-Atmos., 105, 24809-24822, doi:10.1029/2000jd900327, 2000.

Lin, J.-T. and McElroy, M. B.: Impacts of boundary layer mixing on pollutant vertical profiles in the lower troposphere: Implications to satellite remote sensing, Atmos. Environ., 44, 17261739, doi:10.1016/j.atmosenv.2010.02.009, 2010.

Lin, S.-J.: A "Vertically Lagrangian" Finite-Volume Dynamical Core for Global Models, Mon. Weather Rev., 132, 2293-2307, doi:10.1175/1520-0493(2004)132<2293:avlfdc>2.0.co;2, 2004.

Lock, A. P., Brown, A. R., Bush, M. R., Martin, G. M., and Smith, R. N. B.: A New Boundary Layer Mixing Scheme. Part I: Scheme Description and Single-Column Model Tests, Mon. Weather Rev., 128, 3187-3199, doi:10.1175/15200493(2000)128<3187:anblms>2.0.co;2, 2000.

Louis, J., Tiedtke, M., and Geleyn, J.: A short history of the PBL parameterization at ECMWF, Workshop on Planetary Boundary Layer Parameterization, ECMWF, Reading, England, 5-27 November 1981, 59-79, 1982.

McMahon, T. A., Finlayson, B. L., Haines, A. T., and Srikanthan, R.: Global Runoff - Continental Comparisons of Annual Flows and Peak Discharges, Catena Verlag, Cremlingen, Germany, 166 pp., 1992.

Molod, A. and Salmun, H.: A global assessment of the mosaic approach to modeling land surface heterogeneity, J. Geophys. Res.Atmos., 107, D14, doi:10.1029/2001jd000588, 2002.

Molod, A., Takacs, L., Suarez, M. J., Bacmeister, J. T., Song, I.S., and Eichmann, A.: The GEOS-5 Atmospheric General Circulation Model: Mean Climate and Development from MERRA to Fortuna, Technical Report Series on Global Modeling and Data Assimilation, 28, 115 pp., available at: http://gmao.gsfc. nasa.gov/pubs/docs/tm28.pdf (last access: 4 March 2014), 2012.

Moorthi, S. and Suarez, M. J.: Relaxed Arakawa-Schubert. A Parameterization of Moist Convection for General Circulation Models, Mon. Weather Rev., 120, 978-1002, doi:10.1175/15200493(1992)120<0978:rasapo>2.0.co;2, 1992.

Nielsen-Gammon, J. W., Powell, C. L., Mahoney, M. J., Angevine, W. M., Senff, C., White, A., Berkowitz, C., Doran, C., and Knupp, K.: Multisensor estimation of mixing heights over a coastal city, J. Appl. Meteorol. Clim., 47, 27-43, doi:10.1175/2007JAMC1503.1, 2008.

Peel, M. C., McMahon, T. A., and Finlayson, B. L.: Continental differences in the variability of annual runoffupdate and reassessment, J. Hydrol., 295, 185-197, doi:10.1016/j.jhydrol.2004.03.004, 2004.

Peel, M. C., Finlayson, B. L., and McMahon, T. A.: Updated world map of the Köppen-Geiger climate classification, Hydrol. Earth Syst. Sci., 11, 1633-1644, doi:10.5194/hess-11-16332007, 2007.

Putman, W. M. and Lin, S.-J.: Finite-volume transport on various cubed-sphere grids, J. Comput. Phys., 227, 55-78, doi:10.1016/j.jcp.2007.07.022, 2007.

Rienecker, M. M., Suarez, M. J., Todling, R., Bacmeister, J. T., Takacs, L., Liu, H.-C., Gu, W., Sienkiewicz, M., Koster, R., Gelaro, R., Stajner, I., and Nielsen, J. E.: The GEOS-5 Data Assimilation System - Documentation of Versions 5.0.1, 5.1.0, and 5.2.0, Technical Report Series on Global Modeling and Data Assimilation, 101 pp., available at: http://gmao.gsfc.nasa.gov/pubs/ docs/GEOS5_104606-Vol27.pdf (last access: 4 March 2014), 2008.

Rienecker, M. M., Suarez, M. J., Gelaro, R., Todling, R., Bacmeister, J., Liu, E., Bosilovich, M. G., Schubert, S. D., Takacs, L., Kim, G. -K., Bloom, S., Chen, J., Collins, D., Conaty, A., da Silva, A., Gu, W., Joiner, J., Koster, R. D., Lucchesi, R., Molod, A., Owens, T., Pawson, S., Pegion, P., Redder, C. R., Reichle, R., Robertson, F. R., Ruddick, A. G., Sienkiewicz, M., and Woollen, J.: MERRA: NASA's Modern-Era Retrospective Analysis for Research and Applications, J. Climate, 24, 3624-3648, doi:10.1175/jcli-d-11-00015.1, 2011.

Sandu, I., Beljaars, A., Bechtold, P., Mauritsen, T., and Balsamo, G.: Why is it so difficult to represent stably stratified conditions in numerical weather prediction (NWP) models?, J Adv Model Earth Syst, 5, 117-133, doi:10.1002/jame.20013, 2013.

Seibert, P., Beyrich, F., Gryning, S. -E., Joffre, S., Rasmussen, A., and Tercier, P.: Review and intercomparison of operational methods for the determination of the mixing height, Atmos. Environ., 34, 1001-1027, doi:10.1016/s1352-2310(99)00349-0, 2000.

Seidel, D. J., Ao, C. O., and Li, K.: Estimating climatological planetary boundary layer heights from radiosonde observations: Comparison of methods and uncertainty analysis, J. Geophys. Res., 115, D16113, doi:10.1029/2009jd013680, 2010.

Seidel, D. J., Zhang, Y., Beljaars, A., Golaz, J.-C., Jacobson, A. R., and Medeiros, B.: Climatology of the planetary boundary layer over the continental United States and Europe, J. Geophys. Res.Atmos., 117, D17106, doi:10.1029/2012jd018143, 2012.

Triantafyllou, G. N. and Tsonis, A. A.: Assessing the ability of the Köppen System to delineate the general world pattern of climates, Geophys. Res. Lett., 21, 2809-2812, doi:10.1029/94g101992, 1994.

Vogelezang, D. H. P. and Holtslag, A. A. M.: Evaluation and model impacts of alternative boundary-layer height formulations, Bound.-Lay. Meteorol., 81, 245-269, doi:10.1007/bf02430331, 1996. 